\title{
A fresh perspective
}

\author{
John Edwards \\ PEC Member
}

The BDJ Upfront section includes editorials, letters, news, book reviews and interviews. Please direct your correspondence to the News Editor,

Adrian O'Dowd at BDJNews@nature.com. Press releases or articles may be edited, and should include a colour photograph if possible.

$\mathrm{I}$ was elected to the Principle Executive Committee (PEC) - the BDA's Board of Directors - in December 2017 from the Northwest England region and I wanted to take the anniversary as an opportunity to describe what I've discovered in my first year.

I was told in my induction that I would have plenty of 'bedtime-reading' for the first year. This has comprised of mainly minutes of previous meetings and a substantial amount about company law and the responsibilities of directors. I have been on a steep learning curve despite being an enthusiastic BDA member since my student days. I have discovered a lot about the broader picture of how the BDA functions and runs its affairs.

The PEC meets five times a year, but there are also monthly updates on the financial situation and membership trends. A vibrant 'chat forum' is available by email for PEC and staff members with contributions regarding the running of the Association and 'burning issues. There are also daily updates prepared by the press and media department on all things 'dental' appearing in the press.

I was surprised about the composition and operation of the PEC. I had imagined a room full of 'old grandees' of the BDA in grey suits who were not necessarily up to date on innovation and new ideas. This was absolutely not the case! Our democratic processes have furnished the PEC with energetic and interested directors ready for change. I do think, though, that it we should encourage more women and younger dentists to get involved. I have enlisted a young, local enthusiastic dentist who I intend to bring along to some of the meetings in London to develop their interest more. I would encourage others to do similar at branch and section level.

Every three years the PEC produces a strategic plan for the Association. In doing so, it consults the membership through detailed surveys and research, and invites staff to give their insights. It takes advice and soundings from the Country Councils and Craft Committees. The senior management team of the BDA provides advice and analysis to inform the planning process and ultimately is responsible for its implementation. I have been part of this year's process.

We are faced with several key issues which present both opportunities and threats. These have driven us to shape and agree the strategic plan. You can see the full text of the plan by following this link: https://go.nature. com/strategicplan. For me personally, the issues that resonate most are the need to make the BDA more attractive and relevant to younger members; the challenges of GDS contract reform; dental education into the future; and GDC reform. committed band of local volunteers and get the right balance of local ownership coupled with central support.

As with anything else, content, price and value are important features that influence people to buy or not buy goods, services and, of course, memberships. We have looked long and hard at what we do and what is included within our offerings. We have thought about whether there are other things that we could include that would make BDA membership even more desirable. We will pursue these considerations and try to make the BDA a 'one-stop-shop' for everything you need as a practising dentist in the UK.

The final element that I have taken particular interest in is the concern that

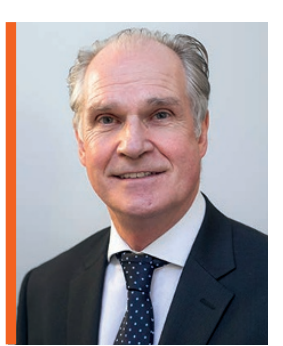

'We need to become more attractive to newly qualified
and younger dentists'
Members are the BDA's lifeblood and my own personal aspiration and goal is to help the BDA to rebuild member numbers. This has been my main interest and contribution into the strategy development process. We need to evaluate our offerings and make them a 'must-have' for all UK dentists. If we are to achieve this we need to become more attractive to newly qualified and younger dentists. The three-year strategic plan reflects these necessary changes and concentrates on four areas of focus - accessibility, engagement, relevance and value. A significant aspect of this is our plan to reform the section and branch structure. Members told us that the local presence and activity of the BDA is something that they really value. We are exploring ways that we can help our hugely members have expressed about the current state of play within the professional indemnity market. They told us loud and clear that they are troubled by the services offered. They have given us a mandate to seek to make meaningful impacts in that area. We have taken them at their word and we have invested a huge amount of energy in investigating professional indemnity. The BDA has begun to engage with the current providers to see if we can effect positive change. We have explored opportunities for collaboration to improve the way that UK dentists are served. We are serious about this and if influence and collaboration aren't enough we will consider all options.

Watch this space. I'm really looking forward to year 2 !

DOI: 10.1038/sj.bdj.2018.1119 